\title{
The Opportunity of the Physics Teacher*
}

\author{
Robert A. Millikan \\ California Institute of Technology, Pasadena. California
}

I T will generally be agreed that physics is the most fundamental of the sciences, that some knowledge of it underlies them all and is therefore their indispensable prerequisite. For this reason alone the job of the teacher of physics takes on unusual significance. But from my point of view it is much more vital in the present stage of development of the United States than most physics teachers themselves realize. The main purpose of this paper is to point out why.

At no time or place in world history has any country, save the United States, attempted to extend to every youth within its borders the benefits of a general education up to the age of from sixteen to eighteen. But within the past forty years forty-two of our states have passed laws requiring school attendance of every boy and girl up to about that age. Some of our European critics call it a fantastic and ridiculous attempt, since so large a fraction of the population, 90 percent at least, it is said, must in any case gain its livelihood in manual or service pursuits of one kind or another.

There are two answers to this criticism. The first is that since all those engaged in the foregoing occupations are in any case voters, it is essential for the preservation of our free, democratic, American way of life that the attempt be made to give all voters sufficient education to enable them to vote intelligently.

The second answer goes farther and asserts that if our democratic way of life is to show itself really superior to other ways, such as the totalitarian way, it must succeed better than any other way both in bringing into leadership in the development of American civilization the ablest and most competent men the country produces and also in fitting each citizen into the niche in society which he is best fitted to occupy and in which he will be most effective for the purposes of society and therefore most happy for the purposes of his own life.

That last "and therefore" attacks, at its base,

* Reply to the presentation of the Oersted Medal, December 30, 1940. the fundamental fallacy that happiness in life has any relation to the magnitude of the responsibilities that one carries or the power that one wields. The gratification of mere physical or biological wants aside, the greatest satisfactions in life come from a sense of mastery of one's job and the greatest misery from a sense of incompetence, inability to succeed in doing well what one is expected to do. The average man is not happy in intellectual pursuits because he does not succeed well enough in them. They are too hard; they give him too many headaches. Educational philosophers and psychologists have repeatedly pointed out that the greatest satisfaction in life for all of us, including even the intellectually competent, comes from the mastery of manual skills such as underlie all sports and a large part of all artistry, in learning by endless repetition to do even service jobs with perfection and dispatch. Vastly more people are interested in art than in knowledge.

If the truth of these assertions is admitted, then the most important job of any universal educational system consists not so much in imparting knowledge, though that, of course, has its place, as in using the educational machinery from the age of thirteen on for the purposes of selection, or better, of vocational guidance, so as to discover just what are the aptitudes, interests and capabilities of each prospective citizen and so as to fit him into the niche in our society in which he can be most useful and therefore most happy. This will consist very much more of ten in steering him away from analytical, intellectual pursuits to which he is not adapted than in steering him into them.

Physics is admittedly the best subject in the whole curriculum for testing the analytical aptitudes and capacities of the student, that is, in finding out whether he is likely to make a success of any of the analytical pursuits such as are all the sciences, law, medicine, engineering, finance, management, government, and so forth. Probably the most kindly, the most humane, act that can be done to nine-tenths of the youth of 
the land is to steer them away from, not toward, these difficult, analytical, intellectual pursuits. Obviously the way to accomplish best this objective of distributing the population most wisely and effectively among the available pursuits is to give as nearly as possible equal opportunity to every youth up to the age of from sixteen to eighteen to show to competent judges what is in him, what kind of capacities and interests and character he has, and to let the kind of vocation which he goes into for earning a living be the kind in which, in this probationary period, he has shown himself best adapted to succeed and be most content.

Let us look first at what kind of qualities in teaching are required to meet the requirements of this second objective of a universal educational system. The answer is quite clear. The most important job of the teacher is to know his students, every one of them, so that he will make as few mistakes as possible in rating their qualities and their capacities justly and accurately in order that he may steer them wisely. Talking entertainingly to a hundred or two hundred students is a wholly subordinate and trivial requirement of a good teacher. The great, indispensable requisite is conscientiousness in watching carefully and discriminatingly the way his students solve problems, the way they do their laboratory work, the way they answer examination questions, the way they pose questions of their own. This job cannot be delegated to anyone else without abdicating the main job of the teacher.

Such abdication may sometimes be necessary when the exigencies of the whole educational machinery require a teacher to change his job and become an administrator instead of a teacher, but even so it is of the utmost importance for the administrator, in performing his new function of selecing good leachers, to know what the prime requirement of a good teacher is, namely, conscientiousness in doing the job of selection and vocational guidance as well as it can be done. No professional guidance person can do that. It is the teacher's own job.

May I now digress one moment to say a word about what kind of steering is to be done for those who are not fitted to go on into the intellectual pursuits? That leads me to comment upon what, in the past, has been the most obvious and lamentable weakness of our whole American educational system, namely, the lack of an apprenticeship system operated in connection with industry into which, at the end of the high school course-the twelfth grade-the student whose place is obviously in the manual callings or in commerce can become expert in these vocations. The British Empire and the whole of Europe have done this job vastly better than have we in the United States. That is why, in the past, most of our skilled mechanics, and even skilled service people, such as waiters in hotels, have had to be imported from abroad. Fortunately this lack has recently been recognized by some of our educational agencies, and they are now beginning to take steps to meet this enormous need.

Let me now go back to the first reason given above for the attempt to keep every youth in the country in the secondary educational system up to the age of from sixteen to eighteen. This attempt has so far succeeded in the United States that, according to official reports of the Department of Education, 66 percent of all the youth of secondary school age is now in school, and in some of the northern states the percentage is as high as 80 .

This situation provides an opportunity such as never existed at any other place or time in history, for the future of any democratic country is assured if it can train 51 percent of its voting population to vote intelligently. With 66 percent of our youth in the secondary school, the school teacher, if he realizes his opportunity, can himself assure the preservation of our democracy, for example, by so educating that 66 percent as to eliminate the greatest internal menace to the future of the United States, namely, our political corruption, euphemistically called the American patronage system, a system which makes Congress the tool of political pressures, whether exercised by bonus racketeers or by unscrupulous elected officials. This system will destroy us if we do not destroy' it, as England has destroyed it within the past hundred years, replacing what was as rotten a system as ours by an amazingly clean, nonpolitical public service-the most important pillar of democracy. Only intelligent voters can do this. Through our public schools 
the feat can be accomplished in one generation. In other words, the future of our country is literally in the hands of the American school teacher.

But how does one learn to vote intelligently? The answer is, by beginning to get in to his consciousness some idea of what is the rational approach to life instead of the irrational, superstitious approach, which was all that primitive man could use and is still used by many who do not realize that they are still primitives.

But what, in turn, is the rational approach? It is the approach that is based on knowledge instead of on ignorance, or prejudice, or hunch, or emotion, or tradition. The most important idea that can get into the minds of the youth of the nation is that there is a core of definite established knowledge in all fields, even the field of government, that must be the starting point and basis of all correct action, all wise conduct. This core is much larger in some fields than in others, and in all fields it is surrounded by a zone of the controversial and this in turn by the "great unknown"; but the first job of education in the intellectual sense consists in getting the student interested in finding out what is in that core and what, therefore, must be the starting point of all his own search for the right course of conduct for himself.

As a rough rule to find what, in a given field, lies within the core of the known, one seeks to discover in what particulars, say, nine-tenths of the recognized and competent authorities in any given field are in agreement. Wherever there is that kind of agreement among the high-minded, competent and recognized students of a field, there is not one chance in a thousand that they are wrong. This particular bit of knowledge, then, with all its inevitable implications can be taken as a safe guide to one's own thinking and acting, including one's voting.

Now, the subject of physics, in which the core of the known is probably larger than in any other field, furnishes the finest possible illustrations of the rational, scientific method of going at all our problems. To take but one simple example, three hundred years ago the law of gravitation was completely unknown, and all kinds of fantastic and superstitious theories were current as to the causes of the apparent motions of the moon and the planets, and the influences of the positions of these bodies upon our lives. Today all these superstitions are gone among thoughtful and intelligent people. No other subject begins to be as fundamental and as rich in its illustrations of the meaning of the rational mode of approach to life.

I was so impressed with the possibilities of educating the whole of the oncoming generation in these fundamentals, now that so large a fraction of it is in the secondary schools, that I discussed with some of my friends the possibility of getting into the curriculum of the schools in some way a book on the social significance and implications of physics. Among us we concluded it was too grandiose a project, involving too big a change in curriculums, for immediate realization, but Professor Gale and I tried to put the idea into effect in a small way in the last rewriting we made of our Elements of Physics.

Up to the present, however, let us admit that our universal educational system to the age of about seventeen has not realized at all this first objective of universal education, namely, the job of providing 51 percent of intelligent voters in the United States. Nevertheless, this much is certain: The physics teacher of the future has here an enormous opportunity which I am confident that in time he will grasp and act upon.

I have discussed with some educators a simple plan which, it seems to me, would be at least a beginning in the right direction. Without attempting to change the curriculums of the schools at all, the suggestion is to utilize the weekly assembly in all secondary schools for a series of movies, which would go in succession into all the schools of the country, presenting elements from the cores of established knowledge upon which there is general agreement, and avoiding all controversial matters, thus trying to provide a basis for the straight thinking of the whole of the coming generation of American voters. Physics would, of course, have to furnish its full share of the illustrations of the rational, scientific approach to life as distinct from the emotional, the prejudiced, the superstitious approach. If once every week during high school years practically the whole of the oncoming generation could be thus exposed in an interesting way merely to the most basic and unquestioned truths that have 
been discovered and are now here ready to serve as a guide to the thinking and acting of each one of us, the basis would be laid for getting a 51 percent intelligent vote. The school teacher has the power to accomplish this in 25 years in the United States. Some physics teacher may have the energy and the brains to meet in this or some other way the great opportunity which our universal educational sy'stem now provides for educating America up to the opportunities and possibilities of the democratic, American way of life.

\title{
A Wind Tunnel for Student Experiments and for Demonstrations
}

\author{
I. F. Zartman and Warren EberLy \\ Mullenberg College, Allentown, Pennsylvania
}

$T^{1}$ HE need for an inexpensive wind tunnel to demonstrate effectively the flow of an air stream past variously shaped objects, to show the effect of streamlining, to make the streamlines visible, and to measure the lift and drag with ease and reproducible results, led to the development of the apparatus described here. The cost, exclusive of the labor, of the completed tunnel was less than $\$ 25.00$. The return-type tunnel was selected to prevent the air stream from being blown throughout the room and to allow the use of confetti or chemical fumes such as $\mathrm{TiCl}_{4}$ in making the streamlines visible without the disagreeable effects experienced with the open type. The support of the various objects and of the balance used to measure lift and drag is greatly facilitated by the open testing chamber of this tunnel; and, at the same time, maximum visibility is provided for class demonstrations. The tunnel serves as an excellent piece of demonstration apparatus as well as the basis for a student experiment in the measurement of lift and drag. ${ }^{1}$

The tunnel, Figs. 1 and 2, is constructed of galvanized stovepiping and elbows 12 in. in diameter with the entrance cone constricted to 8 in. The inside of the exit cone is rounded off with plaster of Paris, and immediately beyond this is placed a ring of "breather holes." Several vanes are fitted into the elbow beyond the "breather holes." These vanes are necessary to reduce the backwash in the testing chamber and assist greatly in removing disturbances from the air stream. The entrance cone is preceded by a

1 A larger wind tunnel of the open type is described by S. R. Williams, Am. J. Phy. (Am. Phys. T.) 3, $t$ (1935). comb in the form of a grill of 2-in. square openings, the grill being made of sheet iron 2 in. wide fitted within the tunnel. Several fins placed in the elbow just preceding the comb aid in straightening out the air stream. The air stream flowing through the testing chamber is found to have practically a constant speed over its entire cross section. According to a communication from the National Advisory Committee for Aeronautics, the relation

$$
d=d_{1}+0.18 L
$$

should exist between the diameter $d$ of the exit cone, the diameter $d_{1}$ of the entrance cone and the distance $L$ between the cones, or the length of the testing chamber.

The propeller, a standard four-blade ventilating type fan 12 in. in diameter, is mounted on a steel shaft operating in bearings adjustable for proper centering. Step pulleys on the shaft and on the $\frac{1}{3}$-hp motor are connected by a V-belt, thus allowing for changes in the speed of the air stream. The propeller rotates in a wooden form which can be opened for adjustments and oiling.

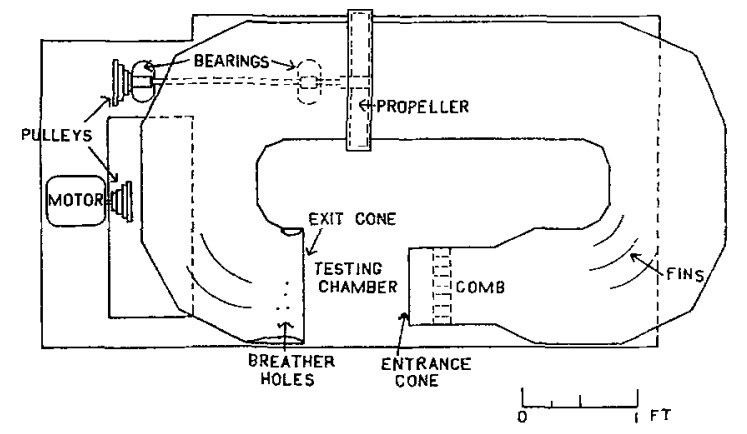

Fig. 1. Top view of wind tunnel. 